\title{
The effect of thermal processing on the content and antioxidant capacity of free and bound phenolics of cookies enriched by nettle (Urtica dioica L.) seed flour and extract
}

\author{
Jelena MITROVIĆ ${ }^{1 \star}$ (D), Nada NIKOLIĆ ${ }^{1}$, Ivana KARABEGOVIĆ ${ }^{1}$, Miodrag LAZIĆ ${ }^{1}$, Ljubiša NIKOLIĆ , \\ Saša SAVIĆ ${ }^{1}$, Mirjana PEŠIĆ ${ }^{2}$, Olivera ŠIMURINA³, Marija STOJANOVIĆ-KRASIĆ ${ }^{1}$
}

\begin{abstract}
The content of free and bound phenolics and their antioxidant capacity in cookies enriched by nettle seed flour and a nettle seed phenolic extract, before, during and after thermal processing (baking at $180^{\circ} \mathrm{C}$ for $25 \mathrm{~min}$ ) were examined. The results compare these properties to a cookie obtained only from wheat flour, as the control. Better results were obtained by incorporating nettle seed flour than nettle seed extract. During thermal processing, different changes of phenolic content and antioxidant capacity (increase, decrease or retention) occurred, depending on the form of the phenolics (free or bound), thermal processing time, the cookie and applied antioxidant assays. The free and bound phenolics in the cookie with seed flour were more stable than in the other cookies. At the end of the thermal processing, the cookie with nettle seed flour had a higher content of free and bound phenolics ( 2.1 and 2.5 times, respectively), and greater antioxidant capacity (the DPPH RSC of free and bound phenolics 9.2 and 4.6 times, and of reducing power 1.6 and 3.4 times, respectively) than the control. There are great possibilities of using nettle seeds in the food industry with the aim of obtaining a functional product with powerful health benefits.
\end{abstract}

Keywords: phenolics; nettle seeds; antioxidant capacity; thermal processing; cookies.

Practical Application: The use of nettle seeds in the food industry to obtain a functional product with powerful health benefits.

\section{Introduction}

Modern society is placing more and more pronounced demands on the issue of food consumption which, in addition to satisfying energy needs and the intake of necessary nutrients, should provide improved health or the prevention of certain diseases. The food industry is increasingly focused on improving the quality and health benefit of its products. Therefore, numerous studies (Tyagi et al., 2020; Bhat et al., 2020; Kaur et al., 2017; Aksoylu et al., 2015) have dealt with the incorporation of different plants and their parts (nettle, Tinospora cordifolia, tomato, flaxseed, blueberry, grape and poppy seed) as supplements for bakery products based on cereals, usually wheat, in order to increase their nutritional value and antioxidant properties.

Stinging nettle (Urtica dioica L.) is a perennial flowering plant belonging to the Urticaceae family. It is known as a cosmopolitan plant, widespread in temperate and tropical areas (Yener et al., 2009). Nettle is a good source of minerals, especially iron, vitamin C and pro-vitamin A (Cowan, 1999), but it is also extremely rich in protein, carbohydrates and fats. Adhikari et al. (2015) reported that a nettle leaf contains approximately $33 \%$ proteins and approximately $37 \%$ carbohydrates. Compared to regular cereals as a source of protein, a nettle leaf contains 3.2 times higher amount of proteins than wheat flour. Although a nettle leaf contains a high content of carbohydrates, it is significantly lower compared to the carbohydrate content of wheat (86.5\%) (Adhikari et al., 2015).
Other research into nettle indicates that it is an herb with a very pronounced antioxidant potential, but is also known for a wide range of other activities such as antimicrobial, antiulcerogenic, analgesic, diuretic, antidiabetic, anti-inflammatory and antirheumatic (Gülçin et al., 2004; Vajić et al., 2015; Zeković et al., 2017; Khare et al., 2012). There are numerous indications of nettle being used in medicine due to its positive effects on human health. Its antioxidants, including phenolics, play a key role in human health. The health biological activity allows phenolics to be suitable for numerous food preservation applications. Therefore, different kinds of products can be fortificated with phenolics to extend the shelf life of some foods, to turn them in functional food or to incorporate them in food packaging (Martillanes et al., 2017). The presence of phenolics in products has been also associated with sensory quality (color, flavor and astringency) of products. Thus, flavonols, e.g. kaempferol glycosides, and catechins, e.g., catechin gallate, were highly positively related to bitterness, astringency and pea-pod taste. Some volatile polyphenols, e.g., vanillin and eugenol, are strong odorants. Guaiacol, $p$-cresol, creosol and 2-phenylethanol have a high odor-impact to flavor of Vanilla planifolia, while guaiacol, creosol, $p$-vinyl guaiacol were identified as key components for "smoky" notes in Tahitian vanilla flavor (Troszyńska et al., 2011; Brunschwig et al., 2012; Dignum et al., 2004). 
The phenolics are present in free and bound forms. The free phenolics are solvent extractable by water or aqueous/organic solvents mixtures. The bound phenolics are usually covalently bound to cell wall structural components (cellulose, hemicellulose, lignin, pectin and structural proteins) and by acid or alkaline hydrolysis they can be liberated from cell wall. Unlike free, the bound phenolics cannot be absorbed in the small intestine, but in the colon they undergo fermentation by the colon microbiota and become usable (Shahidi \& Yeo, 2016). Our previous study states that the content of free and bound phenolics in nettle seeds is significant and accounts for $6000.71 \mu \mathrm{g}$ of gallic acid equivalent per $\mathrm{g}$ of dry mass $\left(\mathrm{GAE} \mathrm{g}^{-1}\right)$ and $2801.16 \mu \mathrm{g} \mathrm{GAE} \mathrm{g}^{-1}$, respectively (Mitrović et al., 2020). Compared to wheat flour whose content was $1.31 \mathrm{mg} \mathrm{GAE} \mathrm{g}^{-1}$ (Adhikari et al., 2015), nettle seeds contain a significantly higher content of free phenolics.

The incorporation of nettle leaf and extract in the formulation of products has been investigated and showed the technological quality, nutritional and functional value of cookies has been improved (Đurović et al., 2020; Rutakhli et al., 2019), and thermal processing usually increased the content of phenolics, such as phenolic acids, tanins and flavonoids (Alide et al., 2020; Călinoiu \& Vodnar, 2019). As in the literature there are data about incorporation of nettle leaves (Đurović et al., 2020) but no data about nettle seeds, in this paper, wheat flour-based cookies were made with the addition of nettle seeds (CWS) and phenolics extracted from nettle seeds (CWE) in order to evaluate the effect of incorporating nettle seeds on the their antioxidant potential. Due to phenolics having possible biological effects, and the food processing affecting their stability and bioavailability, it is necessary to evaluate the changes in phenolic content during processing. The content of free and bound phenolics and their antioxidant capacity by using two methods, during thermal processing (baking at $180^{\circ} \mathrm{C}$ for $25 \mathrm{~min}$ ), were examined. The results are compared to the properties of a cookie without a nettle seed component as a control cookie (CC).

\section{Materials and methods}

\subsection{Materials}

The Urtica dioica L. seeds were purchased from "Jeligor", Svrljig in Serbia $\left(43.4146^{\circ} \mathrm{N}, 22.1271^{\circ} \mathrm{E}\right)$, milled in an electric mill (Bosh, MKM 600, Germany) and sieved through a $0.40 \mathrm{~mm}$ riddle to get nettle seed flour.

The wheat flour, type 500, produced by 'DON-DON', Novi Beograd, Serbia, was purchased from a retail market in Leskovac, Serbia. Other cookie ingredients including margarine (Vital, Vrbas, Serbia), baking powder (Centroproizvod, Surčin, Serbia), sugar (Centroproizvod, Surčin, Serbia) were all purchased from a local market in Leskovac, Serbia.

\subsection{The nettle seed extract}

The phenolic extract was obtained by the extraction of phenolic compounds from nettle seeds by using water at a ratio of $1: 10 \mathrm{w} / \mathrm{v}$, at room temperature for $24 \mathrm{~h}$, with occasional stirring.

\subsection{Cookies preparation}

In order to obtain the cookie enriched by nettle seeds (CWS), $350 \mathrm{~g}$ of wheat flour, $150 \mathrm{~g}$ of nettle seed flour, $5 \mathrm{~g}$ of baking powder, $50 \mathrm{~g}$ of margarine, $150 \mathrm{~g}$ of sugar and $200 \mathrm{~mL}$ of water were manually mixed. The obtained dough was rolled out into disks $(4.5 \mathrm{~cm}$ in diameter and $1 \mathrm{~cm}$ in height), and the first half of the rolled dough was processed at $30^{\circ} \mathrm{C}$ for $4 \mathrm{~h}$, milled and sieved through a $0.40 \mathrm{~mm}$ sieve to obtain a sample before thermal processing. The second half was processed in an oven (Candy FPP403 Plan Light Fan Oven, Brugherio, Italy) at $180^{\circ} \mathrm{C}$ for 10,20 and $25 \mathrm{~min}$, cooled to ambient temperature, milled and sieved through a $0.40 \mathrm{~mm}$ sieve to obtain a sample after thermal processing.

The cookie containing nettle seed extract (CWE) was prepared following the same recipe, with the exception that wheat flour was used instead of nettle seed flour, and nettle seed extract $\left(\mathrm{C}_{\text {dry extract }}=13.85 \mathrm{mg} \mathrm{mL}^{-1}, \mathrm{C}_{\text {phenolics }}=410.18 \mu \mathrm{g}\right.$ $\mathrm{mL}^{-1}$ of extract) was used instead of water. Samples before and after thermal processing were obtained in the same manner as the cookie enriched by nettle seeds.

The control cookie (CC) was obtained following the same recipe used for the cookie with nettle seed extract, except that water was used instead of the nettle seed extract, while the sample before and after thermal processing was obtained in the same manner as the cookie enriched by nettle seeds.

\subsection{Extraction of free and bound phenolics}

The extraction of free phenolics was done from $10 \mathrm{~g}$ of the studied samples which were soaked in $50 \mathrm{~mL}$ of $70 \%$ methanol (methanol:water, 70:30 v/v) at room temperature for $24 \mathrm{~h}$, with occasional stirring. Thereafter, the liquid extract was separated from the solids by filtration, and the solids were re-extracted by $70 \%(\mathrm{v} / \mathrm{v})$ methanol and filtered. The filtrates were combined and a final volume of $50 \mathrm{~mL}$ was made. In order to investigate the content of bound phenolic compounds, samples from which free phenolics had previously been removed were primarily subjected to alkaline hydrolysis, as described by Verma et al. (2009). For the DPPH radical scavenging capacity (DPPH RSC) and reducing power measurements, the extracts of free and bound phenolics were evaporated in a vacuum at $40{ }^{\circ} \mathrm{C}$ to dryness, and the dry residue was redissolved in $20 \mathrm{~mL}$ of hot methanol $\left(35^{\circ} \mathrm{C}\right)$. To obtain different concentrations of the extracts, the appropriate dilutions at a ratio from 1:1 to $1: 10 \mathrm{v} / \mathrm{v}$ were made. Such prepared methanolic solutions were filtered through $0.45 \mu \mathrm{m}$ Millipore filters and used for analysis.

\subsection{Phenolic content}

The phenolic content was determined according to the procedure proposed by Singleton \& Rossi (1965), by using the Folin-Ciocalteu reagent. The extract of free and bound phenolics $(0.5 \mathrm{~mL})$ was mixed with $0.5 \mathrm{~mL}$ of the Folin-Ciocalteu reagent and $4.5 \mathrm{~mL}$ of deionised water, and $7.5 \%$ aqueous $\mathrm{Na}_{2} \mathrm{CO}_{3}(5 \mathrm{~mL}$, w/v) was added after $5 \mathrm{~min}$. After $90 \mathrm{~min}$ of incubation, the absorbance was measured at $765 \mathrm{~nm}$ by using a UV 2100 Spectrophotometer (Cole Parmer Instrument Company, Vernon Hills, Illinois, USA). The phenolic content was calculated based on the calibration curve obtained with gallic acid and expressed as $\mu \mathrm{g}$ of gallic acid equivalent (GAE) per g of cookie. 


\subsection{Antioxidant capacity}

The DPPH radical scavenging capacity (DPPH RSC) of the extracts of free and bound phenolics was determined by the method described by Mensor et al. (2001). Absorbance at $517 \mathrm{~nm}$ was measured and converted into the percentage of radical SC (Equation 1):

$$
\mathrm{RSC}=100-\frac{\left(\mathrm{A}_{\text {sample-}} \mathrm{A}_{\text {blank }}\right)}{\mathrm{A}_{\text {control }}} \times 100
$$

where $\mathrm{A}_{\text {sample }}$ is the absorbance at $517 \mathrm{~nm}$ of the methanol solution of the extract treated by the DPPH radical solution, $\mathrm{A}_{\text {blank }}$ is the absorbance at $517 \mathrm{~nm}$ of the methanol solution of the extract ( $1 \mathrm{~mL}$ of methanol added to $2.5 \mathrm{~mL}$ of the extract), and $\mathrm{A}_{\text {control }}$ is the absorbance at $517 \mathrm{~nm}$ of the methanol solution of the DPPH radical ( $1 \mathrm{~mL}$ of a $0.3 \mathrm{mM}$ added to $2.5 \mathrm{~mL}$ of methanol). The reducing power of the extracts was determined by using the Oyaizu (1986) method and by measuring absorbance at $700 \mathrm{~nm}$. Various concentrations of the dry residue of extracts of free and bound phenolics were mixed with $2.5 \mathrm{~mL}$ of a $0.2 \mathrm{M}$ phosphate buffer ( $\mathrm{pH} 6.6$ ) and $2.5 \mathrm{~mL}$ of potassium ferricyanide (1\%). The mixture was incubated at $50^{\circ} \mathrm{C}$ for $20 \mathrm{~min}$. Then, $2.5 \mathrm{~mL}$ of trichloroacetic acid (10\%) was added and the mixture was centrifuged at $3000 \mathrm{rpm}$ for $10 \mathrm{~min}$. Supernatant $(2.5 \mathrm{~mL})$ was mixed with redistilled water $(2.5 \mathrm{~mL})$ and $0.5 \mathrm{~mL}$ of a ferric chloride solution $(0.1 \%)$. The DPPH and reducing power tests were performed in triplicate and the mean value was calculated. Using OriginPro 8 SRO software (OriginLab Corporation, Northampton, USA), the $\mathrm{IC}_{50}$ value was determined and expressed as $\mathrm{mg}$ of the dry residue per $\mathrm{mL}$.

\subsection{Technological properties}

Some technological properties of CWS, CWE and CC, such as the volume, mass and "holding" value (HV), before and during the thermal processing (after 10, 20 and $25 \mathrm{~min}$ ) were determined. The volume of cookies was determined by millet seed displacement method, the mass was measured after cooling the cookies to room temperature, and "holding" value was calculated as the quotient of the height and diameter of the cookies.

\subsection{Statistical analysis}

Statistical analysis was performed by using the analysis of variance (ANOVA) in JMP Statistical Discovery v10.0 software, followed by Tukey's HSD post-hoc test. A probability value of $\mathrm{p}<0.05$ was regarded as a statistically significant difference.

\section{Results and discussion}

\subsection{Phenolic content}

The mean values with standard deviations of the content of free and bound phenolics of the CWS, CWE and CC and their changes during $25 \mathrm{~min}$ of the thermal processing at a constant temperature of $180^{\circ} \mathrm{C}$, are shown in Figure 1 . The results relating to cookies before thermal processing showed that the incorporation of the nettle seed flour, as well as the nettle seed extract, increases the content of phenolics, both free and bound, compared to the CC: the content of free and bound phenolics in the CWS was higher, by 50.2 and $74.3 \%$, respectively, and in the CWE the content was higher by 13.9 and $8.9 \%$, respectively.

The results showed the content of free and bound phenolics varied depending on thermal processing time and a different response of the studied cookies was obtained. Figure la shows the content of free phenolics of the CWS significantly $(\mathrm{p}<0.05)$ increases during $20 \mathrm{~min}$ of thermal processing. The increase was slower in the first $10 \mathrm{~min}$, and faster in the next $10 \mathrm{~min}$, so the maximum value of $2537.18 \mu \mathrm{g} \mathrm{g}^{-1}$ was reached after $20 \mathrm{~min}$ and further changes are not statistically significant. This is probably due to in first $10 \mathrm{~min}$ some of non-phenolic reducing compounds, which also react with Folin-Ciocalteu's reagent, are released and increase the phenolic content (Ikawa et al., 2003). On the other hand, in a period from 10 to $20 \mathrm{~min}$ of processing a faster increasing of the phenolic content is probably due to the part of the bound phenolics is released and appear as free. In support of this is the fact that the content of bound phenolics reduces in this period, which can be seen in Figure 1b. The constant content of phenolics in the period from 20 to $25 \mathrm{~min}$ of thermal processing can be explained by the thermal stability of phenolics from nettle seeds at the investigated temperature.

In the CWE, the content of free phenolics significantly $(\mathrm{p}<0.05)$ decreased in the first $10 \mathrm{~min}$, and in the next $15 \mathrm{~min}$ a statistically significant $(\mathrm{p}<0.05)$ recovery of approximately $12 \%$ was observed, but initial content was not reached. In the $\mathrm{CC}$, similar changes as in the CWE were observed during thermal processing, indicating the free phenolics of wheat flour and phenolics extracted from nettle seeds probably underwent irreversible thermal degradation.

Figure $1 \mathrm{~b}$ indicates the statistically significant $(\mathrm{p}<0.05)$ increase in the content of bound phenolics for the CWS cookie in the first $10 \mathrm{~min}$ of baking. However, in the next $15 \mathrm{~min}$ this content significantly decreases by $16.27 \%$. Contrary to the CWS, in the CWE the content of bound phenolics significantly decrease in the first $10 \mathrm{~min}$, then increase during the next $10 \mathrm{~min}$, and after that re-decreased. The achieved content was lower than the initial one. The change in the bound phenolics in the CC cookie, as in the case of free phenolics, was similar to that of the CWE. This indicates the phenolics extracted from nettle seeds change in the same way as the phenolics of wheat flour during thermal processing, probably due to their similar phenolic composition.

It is evident that during thermal processing an increase and decrease of phenolic content occurred. The increase in the content of free phenolics during thermal processing could be a consequence of the dissociation of bound phenolic moiety (Dewanto et al., 2002), followed by polymerization and oxidation reactions, as well as the formation of new phenolic compounds (Ifie \& Marshall, 2018; Ragaee et al., 2014) which were not present before thermal processing. The formation of Maillard reaction products (MRPs) could also contribute to an increase in phenolic content. This is especially due to certain products of the Maillard reactions which have a reductone structure and 


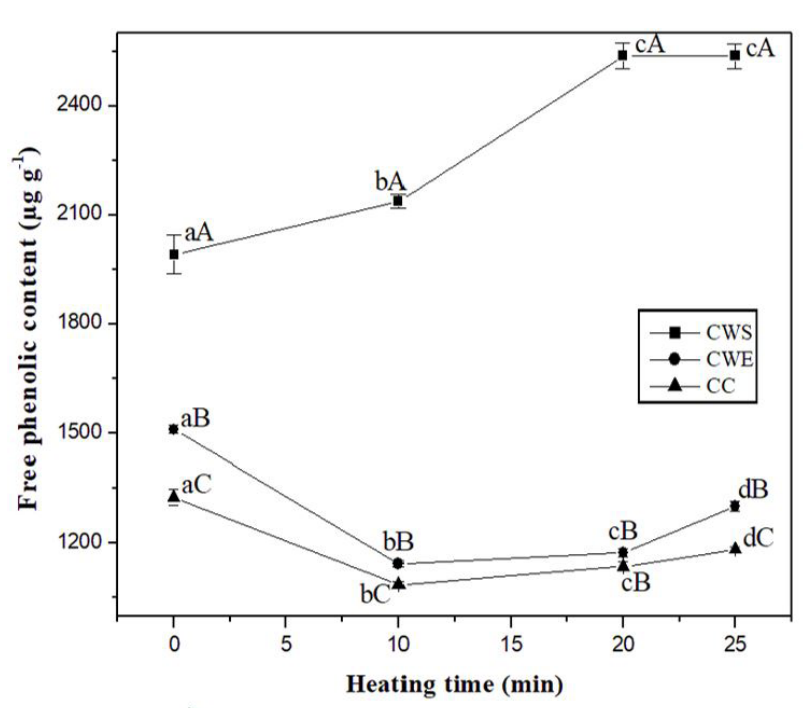

a)

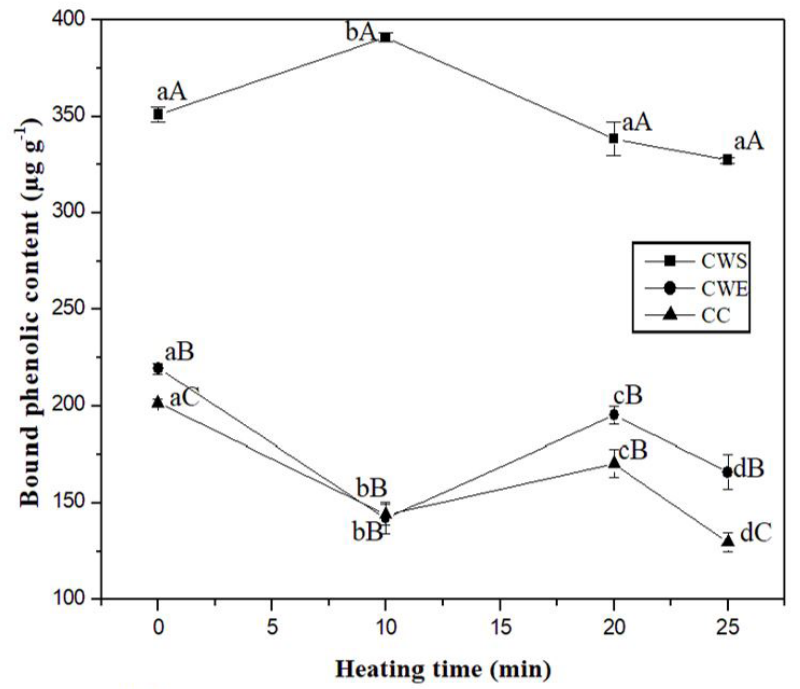

b)

Figure 1. Changes in the content of free (a); bound (b) phenolics in the CWS, CWE and CC during thermal processing; the small letters mark results of Tukey's HSD test during heating time within each cookie; the capital letters mark the Tukey's HSD test between cookies; the same letters indicate there is no significant difference $(p>0.05)$.

react with the Folin-Ciocalteu's reagent, leading to an increase in the content of free phenolics (Žilić et al., 2016). On the other hand, some studies, like Fernandes et al. (2020) showed that composition of phenolics in plant extracts could inhibit Maillard's reactions, and inhibit the formation of advanced glycation end-products. The ability of Folin-Ciocalteu's reagent to react to other compounds besides phenolics is a limitation of method, and chromatographic method for determination the real content and composition of phenolics in these samples may be of interest for future research. The decrease in phenolic content could be a consequence of a great loss of phenolic compounds due to their instability at high temperatures.

At the end of the thermal processing, the content of free phenolics in the CWS was significantly higher $(\mathrm{p}<0.05)$ and amounted to $2537.18 \mu \mathrm{g} \mathrm{g} \mathrm{g}^{-1}$, which is $21.5 \%$ more than the initial level of $1991.75 \mu \mathrm{g} \mathrm{g}^{-1}$. On the other hand, the content of free phenolics in the CWE and CC is slightly different, and the content was significantly lower than their initial one (by $13.85 \%$ and $10.8 \%$, respectively). The thermal processing led to a reduction in bound phenolic content in all of the cookies as well (in the CWS by $6.7 \%$, the CWE by 24.3 and in the CC by $35.6 \%)$. These results are in accordance with the research of Han \& Baik (2008) who found the content of phenolics in lentils, chickpeas and peas was reduced by cooking by $22-42 \%$, and of Nikolić et al. (2016) who found that the content of bound phenolics in wheat flour dough enriched by Boletus edulis was reduced by thermal processing by approximately $7 \%$.

At the end of the thermal processing, when compared to the CC, the CWS had a 2.1 and 2.5 times higher content of free and bound phenolics, and the CWE a 9.9 and $28.0 \%$ higher content, respectively, and the differences in these contents (Figure 1) were statistically significant $(\mathrm{p}<0.05)$.

\subsection{Antioxidant capacity}

In order to investigate the changes of antioxidant capacity during thermal processing, the reciprocal $\mathrm{IC}_{50}$ values were calculated, as the reciprocal $\mathrm{IC}_{50}$ value shows the proper dependence between $\mathrm{IC}_{50}$ and the antioxidant capacity.

Figure 2 shows the reciprocal $\mathrm{IC}_{50}$ values versus heating time. Figures $2 \mathrm{a}, \mathrm{b}$ describe the changes during the thermal processing in the DPPH RSC of free and bound phenolics, respectively, and Figures $2 c, d$ the changes in the reducing power of free and bound phenolics, respectively. The results related to the cookies before thermal processing showed the incorporation of nettle seed flour (CWS) increases the antioxidant capacity of both free and bound phenolics, compared to the CC: the DPPH RSC was 21.4 and 12.2 times higher, respectively, and reducing power was higher by 50.4 and $43.0 \%$, respectively.

The incorporation of nettle seed extract (CWE) also increased the antioxidant capacity of both free and bound phenolics compared to the CC: the DPPH RSC was higher by 1.06 and 1.4 times, respectively, and the reducing power of the free and bound phenolics was higher by $27.5 \%$ and $5.9 \%$, respectively.

In Figure 2a, can be seen that in the case of the CWS there is a decrease in the DPPH RSC of free phenolics by $14.4 \%$ in the first $10 \mathrm{~min}$, which is not statistically significant $(\mathrm{p}>0.05)$. The significant increase develops during further processing up to $25 \mathrm{~min}$, by approximately $32 \%$. A statistically significant decrease in the reducing power of bound phenolics in the CWE and CC (Figure $2 \mathrm{~d}$ ) by $37.1 \%$ and $50.4 \%$, respectively, was observed in the first $10 \mathrm{~min}$. During further processing the reducing power of both cookies was recovered by approximately $30 \%$, but did not reach the initial values. The initial decrease in the antioxidant capacity can be attributed to the thermal degradation of naturally occurring antioxidants as well as the formation of early MRPs with pro-oxidant 

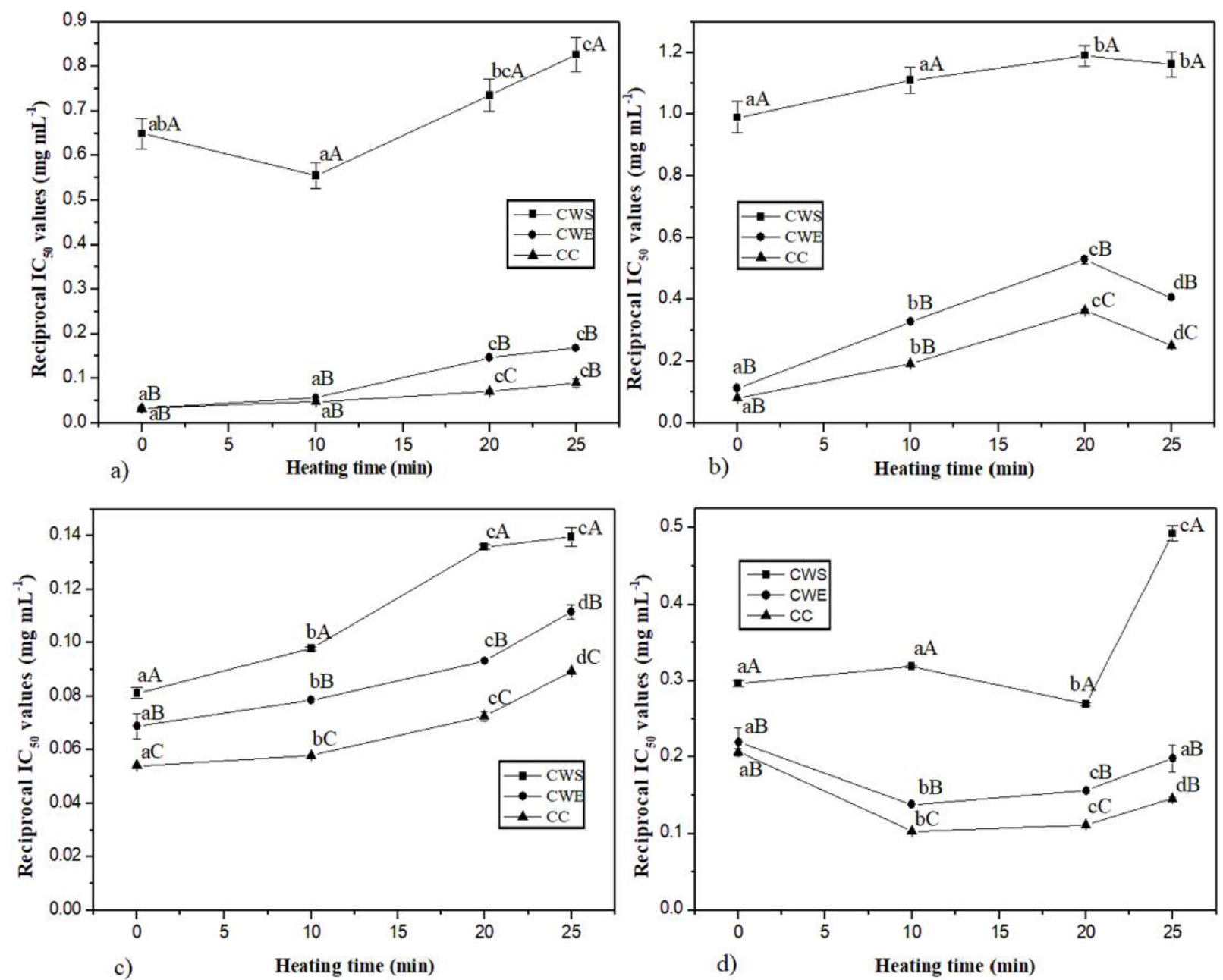

Figure 2. Changes in the antioxidant capacity of free and bound phenolics in cookies during thermal processing, examined by the DPPH method $(a, b)$; the reducing power test $(c, d)$; the small letters mark results of Tukey's HSD test during heating time within each cookie; the capital letters mark the Tukey's HSD test between cookies; the same letters indicate there is no significant difference $(\mathrm{p}>0.05)$.

properties which have mainly been established for MRPs with a low molecular mass, while the antioxidant properties have mainly been attributed to MRPs with a high molecular mass, which are formed in the advanced stages of the reaction (Hofmann et al., 1999). It can be expected that MRPs affect the prolonged shelf life and stability of the obtained cookies and further testing seems to be warranted. Bressa et al. (1996) reported that MRPs produced during the first 20-30 min of cooking showed a high antioxidant capacity, which indicate that MRPs could have an effect on the oxidative stability and shelf life of processed foods. These results were also supported by Nooshkam et al. (2019).

The DPPH RSC of free phenolics in the CWE and CC (Figure 2a) showed a slight retention of antioxidant capacity in the first $10 \mathrm{~min}$ and a steady increase by the end of the process. The retention of antioxidant capacity can be attributed to balancing between the loss of naturally occurring antioxidants and the simultaneous formation of compounds with novel or improved antioxidant properties, while the increase in antioxidant capacity is probably due to the formation of MRPs and the improvement of antioxidant properties of naturally occurring compounds. This phenomenon is also supported by Nicoli et al. (1997), Anese et al. (1999) and Nicoli et al. (1999). A slight retention of antioxidant capacity in the case of the reducing power of bound phenolics in the CWS (Figure 2d) in the first 10 min was also observed, and in further processing it primarily decreased (in the next $10 \mathrm{~min}$ ), then significantly increased (in the last $5 \mathrm{~min}$ ) and exceeded the initial value.

In the case of the DPPH RSC of bound phenolics in all the cookies (Figure 2b), a constant increase of antioxidant capacity in the first $20 \mathrm{~min}$ was observed, and the slight decrease was noticed in the last $5 \mathrm{~min}$. The obtained values are higher than the initial ones. The decrease in the CWS is not statistically significant ( $p>0.05$ ), while in CWE and CC there is statistically significance. This indicates that the bound phenolics from nettle seeds are more stable during heat treatment than bound phenolics from wheat flour and phenolics extracted from nettle seeds.

In the case of the reducing power of free phenolics in all the cookies (Figure 2c), only the constant increase in antioxidant 
capacity during the total duration of the applied thermal processing is shown. In CWE and CC this increase is statistically significant $(\mathrm{p}<0.05)$ in period $0-25 \mathrm{~min}$, and in CWS in period $0-20 \mathrm{~min}$, while in CWS in period 20-25 min there is no statistically significant difference $(\mathrm{p}>0.05)$.

The results showed that different changes in antioxidant capacity occurred during thermal processing, depending on the form of the phenolics (free or bound), and the origin of the polyphenols (from wheat, extract or nettle seeds) and the implemented antioxidant assays (DPPH or reducing power). In the study of Nayak et al. (2015) various antioxidant assays (DPPH, FRAP and ABTS) also had various effects on the antioxidant capacity of heat-treated cookies, and the DPPH assay also contributed to the increase in antioxidant capacity, unlike in the other two assays.

It is evident that at the end of the thermal processing the antioxidant capacity of both free and bound phenolics studied by the DPPH method increased in all the examined cookies. Specifically, at the end of the thermal processing the antioxidant capacity of free phenolics of the CWS increased by $21.43 \%$, while the antioxidant capacity of the CWE and CC increased much more, approximately by $80 \%$ and $66 \%$, respectively. The antioxidant capacity studied as the reducing power of free phenolics also increased during thermal processing in the CWS by $41.8 \%$, and CWE and CC by 38.3 and $39.5 \%$. These increases were statistically significant $(\mathrm{p}<0.05)$.

In the case of bound phenolics, the DPPH RSC in the CWS after thermal processing increased significantly by $14.8 \%$, and in the CWE and CC, as in the case of free phenolics, increased much more, by $72.1 \%$ and $67.8 \%$, respectively. The reducing power showed a different response to thermal processing: the reducing power of bound phenolics in the CWS increased during thermal processing by approximately 39\%, but in the CWE and CC it decreased by 9.7 and $29.5 \%$, respectively. This is probably due to the lower content of bound phenolics with a reducing power in the wheat flour and in the nettle seed extract than in the nettle seed flour. Also, Ragaee et al. (2014) reported the ratio between various phenolics may change due to thermal degradation, causing the appearance of compounds with a lower power of reduction.

A comparison of the cookies showed that the CWS had the highest antioxidant capacity after thermal processing, then the CWE and finally the CC, indicating the incorporation of nettle seed flour (CWS) increased the DPPH RSC of free and bound phenolics 9.2 and 4.6 times, and the reducing power 1.6 and 3.4 times, respectively. On the other hand, the incorporation of the phenolics extracted from nettle seeds (CWE) increased the DPPH RSC of free and bound phenolics 1.9 and 1.6 times, respectively, and reducing power 1.25 and 1.36 times, respectively. These results are congruent with the investigation of Ajila et al. (2008) who reported that a higher level of mango peel powder in biscuits led to a higher DPPH RSC. An increase in antioxidant capacity by $44 \%$ was also obtained by Dewanto et al. (2002) after thermal processing of sweet corn at $100-121^{\circ} \mathrm{C}$ for $10-50 \mathrm{~min}$. Contrary to these results, Eadmusik et al. (2019) reported a decreased DPPH RSC of free phenolics extracted from the Yanang (Tiliacora triandra) leaf during heating for $15 \mathrm{~min}$ at different heating temperatures, and the reason could be the different nature of the endogenous and heat-induced antioxidants and shorter time of thermal processing.

\subsection{Technological properties}

The results of investigations of technological properties of cookies i.e. change of volume, mass and HV during thermal processing are presented in Figures $3 \mathrm{a}-\mathrm{c}$, respectively. The results of change in volume show the existence of three periods: the first from 0 to $10 \mathrm{~min}$, the second from 10 to $20 \mathrm{~min}$ and the third one from 20 to $25 \mathrm{~min}$. At the beginning, in the first period, a constant and statistically significant $(p<0.05)$ increase in volume is observed in all samples (Figure $3 \mathrm{a}$ ), due to a hot air start to distribute inside the cookies. In the second period, the volume

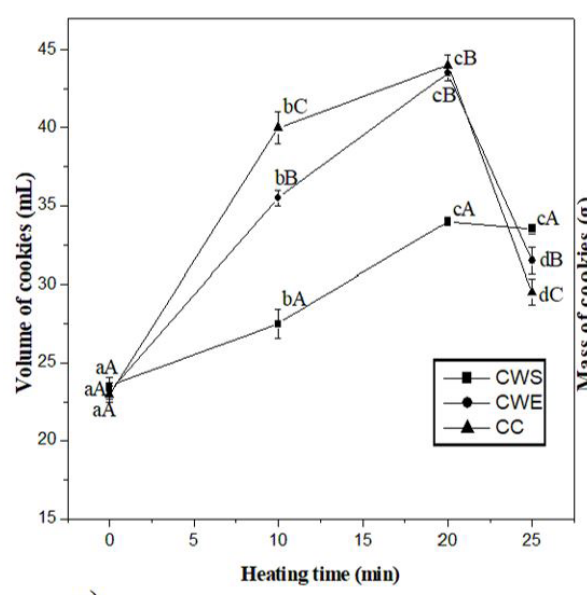

a)

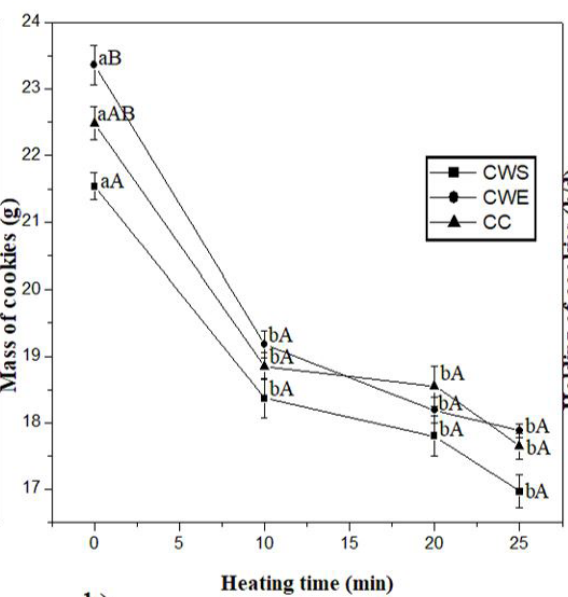

b)

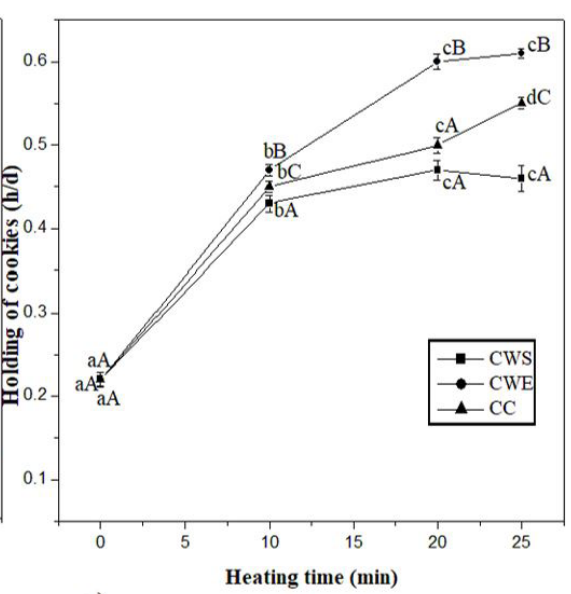

c)

Figure 3. Changes in the technological properties in cookies during thermal processing, examined by volume (a); mass (b); "holding" value (c); the small letters mark results of Tukey's HSD test during heating time within each cookie; the capital letters mark the Tukey's HSD test between cookies; the same letters indicate there is no significant difference $(\mathrm{p}>0.05)$. 
continues to rise and reaches a maximum in the twentieth minute of thermal processing. During these two periods, water evaporates from the cookies, which confirms the decrease in mass in all samples (Figure 3b) due to heat continue to penetrate inside cookies (Sani et al., 2014). In third period statistically significant decrease of volume occurred in CWE and CC, while in CWS volume remains same (there is no statistically significant difference). The decrease in volume can be related to the release of the created carbon dioxide gas. Water continues to evaporate from all cookies (in Figure $3 \mathrm{~b}$ the decrease of mass of all cookies can be seen), but as in case of volume, these differences are not statistically significant. Among samples, there are statistically significant differences regard their volume, and CWS sample had the highest one.

The change of HV during thermal process shows statistically significant increase, in all samples in the period up to $20 \mathrm{~min}$, while in period from 20 to $25 \mathrm{~min}$ in CC, the "holding" value continues to rise, and differences are the statistically significant. In the case of CWS and CWE the change of HV is not significant and it can be considered that there is no change this value. Among samples there are statistically significant differences after $25 \mathrm{~min}$ of thermal processing.

The HV can be considered as a value related to hardness, where a higher value of $\mathrm{HV}$ indicates lower hardness. The highest hardness had CWS and the lowest CWE and this is accordance to results of Đurović et al. (2020) who found the addition of nettle leaves and extract increased the hardness of bread, but extract in lower rate than leaves. The reason for this might be the minerals from plant material, regardless of whether from leaves or seed: when plant material is used in recipe, minerals are introduced into cookies and become their integral part and contribute to higher hardness.

\section{Conclusion}

It has been proven the nettle seed is a good source of phenolics as natural antioxidants. By incorporating nettle seed in form of flour or aqueous extract of phenolics into wheat flour based cookies, a cookies with a higher phenolic content and antioxidant capacity than cookies with wheat flour only, were obtained. The addition of nettle seed flour is much more rewarding than the addition of the extract, as after thermal processing the cookies with nettle seeds had a total phenolic content (the sum of free and bound phenolics) 1.9 times higher than the cookies with the extract. The thermal processing and its time duration significantly influence the content and antioxidant capacity of free and bound phenolics. Especially in cookies with seed flour, baking at $180^{\circ} \mathrm{C}$ for $25 \mathrm{~min}$ significantly increased the antioxidant capacity and phenolic content, with the exception is content of bound phenolics, where thermal processing decreased this content, but decrease was not statistically significant. The phenolics in the cookies with seed flour were also more stable than in the other cookies. The investigations of technological properties of cookies showed the cookie with nettle seed flour had the best volume which is one of desirable property of food products. These points to the great possibility of using nettle seed in the food industry with the aim of obtaining functional products with higher antioxidant capacity and powerful health benefits.

\section{Conflict of interest}

The Authors declare that there is no conflict of interest.

\section{Funding}

This research did not receive any specific grant from funding agencies in the public, commercial, or not-for-profit sectors.

\section{Acknowledgements}

Republic of Serbia - Ministry of Education, Science and Technological Development, Program for financing scientific research work, number 451-03-9/2021-14/200133.

\section{References}

Adhikari, B. M., Bajracharya, A., \& Shrestha, A. K. (2015). Comparison of nutritional properties of Stinging nettle (Urtica dioica) flour with wheat and barley flours. Food Science \& Nutrition, 4(1), 119-124. http://dx.doi.org/10.1002/fsn3.259. PMid:26788318.

Ajila, C. M., Leelavathi, K., \& Prasada Rao, U. J. S. (2008). Improvement of dietary fiber content and antioxidant properties in soft dough biscuits with the incorporation of mango peel powder. Journal of Cereal Science, 48(2), 319-326. http://dx.doi.org/10.1016/j.jcs.2007.10.001.

Aksoylu, Z., Çağindi, Ö., \& Köse, E. (2015). Effects of blueberry, grape seed powder and poppy seed incorporation on physicochemical and sensory properties of biscuit. Journal of Food Quality, 38(3), 164-174. http://dx.doi.org/10.1111/jfq.12133.

Alide, T., Wangila, P., \& Kiprop, A. (2020). Effect of cooking temperature and time on total phenolic content, total flavonoid content and total in vitro antioxidant activity of garlic. BMC Research Notes, 13(1), 564. http://dx.doi.org/10.1186/s13104-020-05404-8. PMid:33317599.

Anese, M., Manzocco, L., Nicoli, M. C., \& Lerici, C. R. (1999). Antioxidant properties of tomato juice as affected by heating. Journal of the Science of Food and Agriculture, 79(5), 750-754. http://dx.doi.org/10.1002/ (SICI)1097-0010(199904)79:5<750::AID-JSFA247>3.0.CO;2-A.

Bhat, N. A., Wani, I. A., \& Hamdani, A. M. (2020). Tomato powder and crude lycopene as a source of natural antioxidants in whole wheat flour cookies. Heliyon, 6(1), e03042. http://dx.doi.org/10.1016/j. heliyon.2019.e03042. PMid:31989047.

Bressa, F., Tesson, N., Dalla Rosa, M., Sensidoni, A., \& Tubaro, F. (1996). Antioxidant effect of Maillard reaction products: application to a butter cookie of a competition kinetics analysis. Journal of Agricultural and Food Chemistry, 44(3), 692-695. http://dx.doi. org/10.1021/jf950436b.

Brunschwig, C., Senger-Emonnot, P., Aubanel, M. L., Pierrat, A., George, G., Rochard, S., \& Raharivelomanana, P. (2012). Odor-active compounds of Tahitian vanilla flavor. Food Research International, 46(1), 148-157. http://dx.doi.org/10.1016/j.foodres.2011.12.006.

Călinoiu, L. F., \& Vodnar, D. C. (2019). Thermal processing for the release of phenolic compounds from wheat and oat bran. Biomolecules, 10(1), 21. http://dx.doi.org/10.3390/biom10010021. PMid:31877857.

Cowan, M. M. (1999). Plant products as antimicrobial agents. Clinical Microbiology Reviews, 12(4), 564-582. http://dx.doi.org/10.1128/ CMR.12.4.564. PMid:10515903.

Dewanto, V., Wu, X., \& Liu, R. H. (2002). Processed sweet corn has higher antioxidant activity. Journal of Agricultural and Food Chemistry, 50(17), 4959-4964. http://dx.doi.org/10.1021/jf0255937. PMid:12166989. 
Dignum, M. J. W., Van Der Heijden, R., Kerler, J., Winkel, C., \& Verpoorte, R. (2004). Identification of glucosides in green beans of Vanilla planifolia Andrews and kinetics of vanilla $\beta$-glucosidase. Food Chemistry, 85(2), 199-205. http://dx.doi.org/10.1016/S03088146(03)00293-0.

Đurović, S., Vujanović, M., Radojković, M., Filipović, J., Filipović, V., Gašić, U., Tešić, Ž., Mašković, P., \& Zeković, Z. (2020). The functional food production: application of stinging nettle leaves and its extracts in the baking of a bread. Food Chemistry, 312, 126091. http://dx.doi. org/10.1016/j.foodchem.2019.126091.

Eadmusik, S., Phungamngoen, C., \& Choosuk, N. (2019). Kinetic degradation of total phenolic content, DPPH Radical scavenging and xanthine oxidase inhibitory activities in Yanang (Tiliacora triandra) leaf extract during preparation process. The Malaysian Journal of Analytical Sciences, 23(3), 516-523.

Fernandes, A. C. F., Vieira, N. C., Santana, Á. L., Gandra, R. L. de P., Rubia, C., Castro-Gamboa, I., Macedo, J. A., \& Macedo, G. A. (2020). Peanut skin polyphenols inhibit toxicity induced by advanced glycation end-products in RAW264.7 macrophages. Food and Chemical Toxicology, 145, 111619. http://dx.doi.org/10.1016/j. fct.2020.111619. PMid:32791243.

Gülçin, I., Küfrevioğlu, Ö. I., Oktay, M., \& Büyükokuroğlu, M. E. (2004). Antioxidant, antimicrobial, antiulcer and analgesic activities of nettle (Urtica dioica L.). Journal of Ethnopharmacology, 90(2-3), 205-215. http://dx.doi.org/10.1016/j.jep.2003.09.028. PMid:15013182.

Han, H., \& Baik, B.-K. (2008). Antioxidant activity and phenolic content of lentils (Lens culinaris), chickpeas (Cicer arietinum L.), peas (Pisum sativum L.) and soybeans (Glycine max), and their quantitative changes during processing. International Journal of Food Science \& Technology, 43(11), 1971-1978. http://dx.doi.org/10.1111/j.13652621.2008.01800.x.

Hofmann, T., Bors, W., \& Stettmaier, K. (1999). Studies on radical intermediates in the early stage of the nonenzymatic browning reaction of carbohydrates and amino acids. Journal of Agricultural and Food Chemistry, 47(2), 379-390. http://dx.doi.org/10.1021/ jf980626x. PMid:10563904.

Ifie, I., \& Marshall, L. J. (2018). Food processing and its impact on phenolic constituents in food. Cogent Food \& Agriculture, 4(1), 1507782. http://dx.doi.org/10.1080/23311932.2018.1507782.

Ikawa, M., Schaper, T. D., Dollard, C. A., \& Sasner, J. J. (2003). Utilization of foline ciocalteu phenol reagent for the detection of certain nitrogen compounds. Journal of Agricultural and Food Chemistry, 51(7), 1811-1815. http://dx.doi.org/10.1021/jf021099r. PMid:12643635.

Kaur, M., Singh, V., \& Kaur, R. (2017). Effect of partial replacement of wheat flour with varying levels of flaxseed flour on physicochemical, antioxidant and sensory characteristics of cookies. Bioactive Carbohydrates and Dietary Fibre, 9, 14-20. http://dx.doi.org/10.1016/j. bcdf.2016.12.002.

Khare, V., Kushwaha, P., Verma, S., Gupta, A., Srivastava, S., \& Rawat, A. (2012). Pharmacognostic Evaluation and Antioxidant Activity of Urtica dioica L.. Chinese Medicine, 03(03), 128-135. http://dx.doi. org/10.4236/cm.2012.33021.

Martillanes, S., Rocha-Pimienta, J., Cabrera-Bañegil, M., Martín-Vertedor, D., \& Delgado-Adámez, J. (2017). Application of phenolic compounds for food preservation: food additive and active packaging. In M. Soto-Hernández (Ed.), Phenolic compounds - biological activity. London: IntechOpen.

Mensor, L. L., Menezes, F. S., Leitão, G. G., Reis, A. S., Santos, T. C., Coube, C. S., \& Leitão, S. G. (2001). Screening of Brazilian plant extracts for antioxidant activity by the use of DPPH free radical method. Phytotherapy Research: PTR, 15(2), 127-130. http://dx.doi. org/10.1002/ptr.687. PMid:11268111.

Mitrović, J. S., Karabegović, I. T., Danilović, B. R., \& Lazić, M. M. (2020). Nettle (Urtica dioica L .) seeds as a source of free and bound phenolics: the antioxidant, antimicrobial activity and the composition. Advanced technologies, 9(1), 13-20.

Nayak, B., Liu, R. H., \& Tang, J. (2015). Effect of processing on phenolic antioxidants of fruits, vegetables, and grains-a review. Critical Reviews in Food Science and Nutrition, 55(7), 887-919. http://dx.doi. org/10.1080/10408398.2011.654142. PMid:24915381.

Nicoli, M. C., Anese, M., \& Parpinel, M. (1999). Influence of processing on the antioxidant properties of fruit and vegetables. Trends in Food Science \& Technology, 10(3), 94-100. http://dx.doi.org/10.1016/ S0924-2244(99)00023-0.

Nicoli, M. C., Anese, M., Parpinel, M. T., Franceschi, S., \& Lerici, C. R. (1997). Loss and/or formation of antioxidants during food processing and storage. Cancer Letters, 114(1-2), 71-74. http://dx.doi. org/10.1016/S0304-3835(97)04628-4. PMid:9103257.

Nikolić, N., Stojanović, J., Mitrović, J., Lazić, M., Karabegović, I., \& Stojanović, G. (2016). The antioxidant activity and the composition of free and bound phenolic acids in dough of wheat flour enriched by Boletus edulis after mixing and thermal processing. International Journal of Food Science \& Technology, 51(9), 2019-2025. http:// dx.doi.org/10.1111/ijfs.13172.

Nooshkam, M., Varidi, M., \& Bashash, M. (2019). The Maillard reaction products as food-born antioxidant and antibrowning agents in model and real food systems. Food Chemistry, 275, 644-660. http://dx.doi. org/10.1016/j.foodchem.2018.09.083.

Oyaizu, M. (1986). Studies on products of browning reaction. Antioxidative activities of products of browning reaction prepared from glucosamine. The Japanese Journal of Nutrition and Dietetics, 44(6), 307-315. https://doi.org/10.5264/eiyogakuzashi.44.307.

Ragaee, S., Seetharaman, K., \& Abdel-Aal, E. S. M. (2014). The impact of milling and thermal processing on phenolic compounds in cereal grains. Critical Reviews in Food Science and Nutrition, 54(7), 837-849. http://dx.doi.org/10.1080/10408398.2011.610906. PMid:24499063.

Rutakhli, A., Sabahi, H., \& Riazi, G. H. (2019). Nanocomposite of montmorillonite/nettle extract: a potential ingredient for functional foods development. Journal of Functional Foods, 57, 166-172. http:// dx.doi.org/10.1016/j.jff.2019.04.004.

Sani, N. A., Taip, F. S., Kamal, S. M. M., \& Aziz, N. A. (2014). Effects of temperature and airflow on volume development during baking and its influence on quality of cake. Journal of Engineering Science and Technology, 9(3), 303-313.

Shahidi, F., \& Yeo, J. D. (2016). Insoluble-bound phenolics in food. Molecules, 21(9), 1216. http://dx.doi.org/10.3390/molecules21091216. PMid:27626402.

Singleton, V. L., \& Rossi, J. A. J. (1965). Colorimetry to total phenolics with phosphomolybdic acid reagents. American Journal of Enology and Viticulture, 16(48), 144-158. Retrieved from http://garfield. library.upenn.edu/classics1985/A1985AUG6900001.pdf

Troszyńska, A., Estrella, I., Lamparski, G., Hernández, T., Amarowicz, R., \& Pegg, R. B. (2011). Relationship between the sensory quality of lentil (Lens culinaris) sprouts and their phenolic constituents. Food Research International, 44(10), 3195-3201. http://dx.doi. org/10.1016/j.foodres.2011.08.007.

Tyagi, P., Chauhan, A. K., \& Aparna, (2020). Optimization and characterization of functional cookies with addition of Tinospora cordifolia as a source of bioactive phenolic antioxidants. LWT, 130(March), 109639. http://dx.doi.org/10.1016/j.lwt.2020.109639. 
Vajić, U. J., Grujić-Milanović, J., Živković, J., Šavikin, K., Godevac, D., Miloradović, Z., Bugarski, B., \& Mihailović-Stanojević, N. (2015). Optimization of extraction of stinging nettle leaf phenolic compounds using response surface methodology. Industrial Crops and Products, 74, 912-917. http://dx.doi.org/10.1016/j.indcrop.2015.06.032.

Verma, B., Hucl, P., \& Chibbar, R. N. (2009). Phenolic acid composition and antioxidant capacity of acid and alkali hydrolysed wheat bran fractions. Food Chemistry, 116(4), 947-954. http://dx.doi.org/10.1016/j. foodchem.2009.03.060.

Yener, Z., Celik, I., Ilhan, F., \& Bal, R. (2009). Effects of Urtica dioica L. seed on lipid peroxidation, antioxidants and liver pathology in aflatoxin- induced tissue injury in rats. Food and Chemical Toxicology, 47(2), 418-424. http://dx.doi.org/10.1016/j.fct.2008.11.031. PMid:19073231.

Zeković, Z., Cvetanović, A., Švarc-Gajić, J., Gorjanović, S., Sužnjević, D. Mašković, P., Savić, S., Radojković, M., \& Đurović, S. (2017). Chemical and biological screening of stinging nettle leaves extracts obtained by modern extraction techniques. Industrial Crops and Products, 108(May), 423-430. http://dx.doi.org/10.1016/j.indcrop.2017.06.055.

Žilić, S., Kocadağli, T., Vančetović, J., \& Gökmen, V. (2016). Effects of baking conditions and dough formulations on phenolic compound stability, antioxidant capacity and color of cookies made from anthocyanin-rich corn flour. $L W T, 65,597-603$. http://dx.doi. org/10.1016/j.lwt.2015.08.057. 